\title{
Scleroderma renal crisis with coexisting segmental arterial mediolysis presenting as intraperitoneal bleeding: a case report
}

Shohei Kaneko ${ }^{1,2}$, Eri Watanabe ${ }^{1 *}$, Mai Abe ${ }^{1}$, Shinji Watanabe ${ }^{1}$, Hiroki Yabe ${ }^{1}$, Shigehiro Kojima ${ }^{3}$, Kenji Takagi ${ }^{4}$, Keiji Hirai ${ }^{2}$, Yoshiyuki Morishita ${ }^{2}$ and Chihiro Terai ${ }^{1}$

\begin{abstract}
Background: Segmental arterial mediolysis is a rare nonarteriosclerotic and noninflammatory vascular disease that may cause intraperitoneal bleeding. Scleroderma renal crisis is a rare complication of systemic sclerosis, leading to severe hypertension and renal dysfunction. To the best of our knowledge, this is the first reported case of a patient with concurrent systemic sclerosis with scleroderma renal crisis and pathologically confirmed segmental arterial mediolysis.

Case presentation: We report a case of a 68-year-old Chinese woman diagnosed with systemic sclerosis who was found to have coexisting segmental arterial mediolysis. She presented with back pain, and massive intraperitoneal bleeding was detected by computed tomography. She underwent laparotomy, and the bleeding was found to originate from the gastroepiploic artery. The pathological examination demonstrated gastroepiploic arterial dissection caused by segmental arterial mediolysis. After surgery, she developed severe hypertension with hyperreninemia and progressive renal dysfunction. Given the risk factors of corticosteroid administration and the presence of antiribonucleic acid polymerase III antibody, she was diagnosed with scleroderma renal crisis. The patient was proved to have a very rare case of coexisting scleroderma renal crisis and segmental arterial mediolysis.

Conclusions: There is no known etiological connection between segmental arterial mediolysis and systemic sclerosis or scleroderma renal crisis, but it is possible that coexisting segmental arterial mediolysis and scleroderma renal crisis may have interacted to trigger the development of the other in our patient.
\end{abstract}

Keywords: Gastroepiploic artery aneurysm, Hypertension, Prednisolone, Renal dysfunction, Systemic sclerosis, Vascular disease

\section{Background}

Segmental arterial mediolysis (SAM) is a rare nonarteriosclerotic and noninflammatory vascular disease first described by Slavin et al. in 1976 [1]. SAM often develops in the abdominal visceral arteries, where it forms an aneurysm and causes intraperitoneal bleeding. Emergency surgery or transcatheter arterial embolization are required to treat bleeding due to rupture of SAM [2, 3]. Scleroderma renal crisis (SRC) is a severe and rare complication of systemic sclerosis (SSc), leading to severe hypertension and

\footnotetext{
* Correspondence: eriw@jichi.ac.jp

'Department of Rheumatology, Saitama Medical Center, Jichi Medical University, 1-847 Amanuma-cho, Omiya-ku, Saitama 330-8503, Japan Full list of author information is available at the end of the article
}

progressive renal dysfunction $[4,5]$. Several risk factors have been associated the onset of SRC, including diffuse skin involvement, disease duration $<4$ years, presence of anti-ribonucleic acid (RNA) polymerase III antibodies, and treatment with prednisolone (PSL) $\geq 15 \mathrm{mg} /$ day within the previous 3 months [4, 6-9]. We report a case of a patient with SRC with several risk factors, coincidentally complicated with SAM, presenting as intraperitoneal bleeding.

\section{Case presentation}

In June, a 68-year-old Chinese woman with severe hypertension and renal dysfunction was admitted to our hospital for further treatment. The patient had no remarkable medical history or family history. The patient

(c) The Author(s). 2019 Open Access This article is distributed under the terms of the Creative Commons Attribution 4.0 International License (http://creativecommons.org/licenses/by/4.0/), which permits unrestricted use, distribution, and 
had noticed puffy swollen fingers and leg edema 1 year previously, as well as the gradual development of skin thickening and Raynaud phenomenon. She had been diagnosed with SSc by a local doctor and had been prescribed PSL $20 \mathrm{mg} /$ day 25 days before admission. At 11 days before the current admission, the patient had visited the previous hospital with acute-onset chest and back pain with blood pressure 101/51 $\mathrm{mmHg}$ and pulse rate 111 beats/min, and contrast-enhanced computed tomography (CT) showed massive intraperitoneal bleeding (Fig. 1). At this time, contrast-enhanced CT showed normal findings of renal arteries, and laboratory findings showed serum creatinine $(\mathrm{Cre}) 1.1 \mathrm{mg} / \mathrm{dl}$ and blood urea nitrogen (BUN) $37.4 \mathrm{mg} / \mathrm{dl}$. The patient accordingly underwent emergency laparotomy, and the bleeding from the gastroepiploic artery was stopped surgically. After surgery, she developed severe hypertension (260/ $129 \mathrm{mmHg}$ ) and progressive renal dysfunction (Cre, 6.4 $\mathrm{mg} / \mathrm{dl}$; BUN, $125.3 \mathrm{mg} / \mathrm{dl}$ ). She was transferred to our hospital for further treatment.

On admission, physical examination showed bilateral lower limb edema, trismus, nail fold telangiectasia, and diffuse skin thickening. The patient's modified Rodnan total skin thickness score was 33 points. No lung lesions were detected on chest CT. Laboratory findings (Table 1) showed normocytic, normochromic anemia and severe renal dysfunction with elevated levels of plasma renin activity at $\geq 20 \mathrm{ng} / \mathrm{ml} / \mathrm{h}$ (normal, $0.3-2.9 \mathrm{ng} / \mathrm{ml} / \mathrm{h}$ ) and plasma aldosterone concentration $433 \mathrm{pg} / \mathrm{ml}$ (normal, $35.7-240 \mathrm{pg} /$ $\mathrm{ml}$ ). Immunological tests revealed positive antinuclear antibody and anti-RNA polymerase III antibody. Echocardiography showed mild left ventricular hypertrophy, a small amount of pericardial effusion, preserved ejection fraction of $80 \%$, and no pulmonary hypertension. Renal artery ultrasound examination showed no evidence of renal artery stenosis.

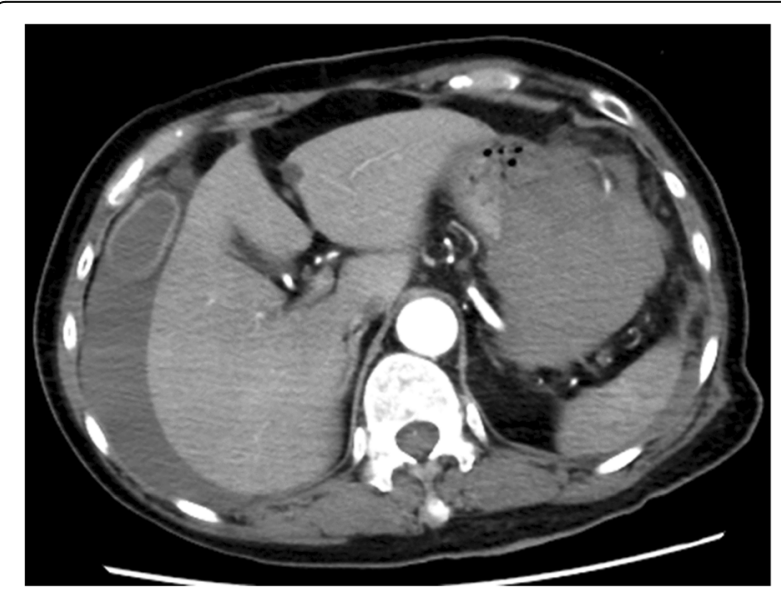

Fig. 1 Contrast-enhanced computed tomography of the abdomen indicated massive intraperitoneal bleeding
The patient was diagnosed with SSc and developed severe hypertension and progressive renal dysfunction with proteinuria and hematuria, thus fulfilling the criteria for SRC $[5,7,10,11]$. The patient also had several risk factors for SRC (duration of disease $<4$ years, diffuse cutaneous form, administration of $\mathrm{PSL} \geq 15 \mathrm{mg} /$ day, and anti-RNA polymerase III antibody) [7-9]. No obvious thrombocytopenia, schistocytes, or elevation of direct bilirubin was present; hence, we had little evidence to diagnosis the patient with complications of thrombotic microangiopathy.

The pathological examination of excised gastroepiploic artery at the previous hospital showed the dissection at the media-adventitia junction, and the dissected cavity was filled with hematoma, indicating gastroepiploic artery aneurysm (Fig. 2a-c). In addition, multiple vacuoles were revealed in the medial muscle layer (Fig. 2d), which was characteristic of SAM $[1,12]$. We diagnosed a gastroepiploic artery aneurysm caused by SAM, with intraperitoneal bleeding due to rupture of the aneurysm. This patient was therefore confirmed as having a very rare case of coexisting SSc with SRC and SAM.

From the first day of admission, she received the angiotensin-converting enzyme inhibitor (ACE-I) enalapril at $5 \mathrm{mg} /$ day, and maintenance hemodialysis was started. PSL was gradually reduced to $2.5 \mathrm{mg} /$ day because of its increased risk of SRC. Her plasma aldosterone concentration decreased gradually (to $75.6 \mathrm{pg} / \mathrm{ml}$ on hospital day 45); however, the control of blood pressure was insufficient, and use of a combination of multiple antihypertensive drugs was required. Eventually, maintenance antihypertensive therapy included enalapril 5 $\mathrm{mg} /$ day, olmesartan $40 \mathrm{mg} /$ day, and nifedipine $80 \mathrm{mg} /$ day. Despite these treatments, her renal dysfunction did not improve at all. She was discharged on hospital day 57 and continued maintenance hemodialysis and blood pressure control thereafter. At the 1-year follow-up visit, she remained on dialysis, and her blood pressure was well-controlled with enalapril $2.5 \mathrm{mg} /$ day and nifedipine $10 \mathrm{mg} /$ day.

\section{Discussion and conclusions}

SAM is a rare vasculopathy characterized by nonarteriosclerotic and noninflammatory vacuolar degeneration of smooth muscle cells of the arterial media, melting of the media, and gap formation. It was reported by Slavin et al. in 1976, but its etiology remains unknown to date [1]. Disruption of the intima allows the remaining adventitia to expand, leading to aneurysm formation [13]. SAM frequently occurs in the abdominal visceral arteries. Inada et al. collected 28 cases of SAM appearing on the abdominal visceral artery and reported that $50 \%$ of SAM occurred in the middle colonic artery, $21 \%$ in the gastric artery, and $18 \%$ in the gastroepiploic artery [2]. 
Table 1 Laboratory data on admission

\begin{tabular}{|c|c|}
\hline Laboratory test & Result \\
\hline \multicolumn{2}{|l|}{ Complete blood count } \\
\hline White blood cells & $16,650 / \mu l$ \\
\hline Neutrophils & $91 \%$ \\
\hline Red blood cells & $264 \times 10^{6} / \mu \mathrm{l}$ \\
\hline Hemoglobin & $8.2 \mathrm{~g} / \mathrm{dl}$ \\
\hline Hematocrit & $25.9 \%$ \\
\hline Mean corpuscular volume & $98 \mathrm{fl}$ \\
\hline Mean corpuscular hemoglobin & $31 \mathrm{pg}$ \\
\hline Platelet & $17.9 \times 10^{4} / \mu \mathrm{l}$ \\
\hline \multicolumn{2}{|l|}{ Coagulation } \\
\hline PT-INR & 1.01 \\
\hline APTT & $31 \mathrm{~s}$ \\
\hline \multicolumn{2}{|l|}{ Biochemistry } \\
\hline Total protein & $5 \mathrm{~g} / \mathrm{dl}$ \\
\hline Albumin & $2.9 \mathrm{~g} / \mathrm{dl}$ \\
\hline Total bilirubin & $0.49 \mathrm{mg} / \mathrm{dl}$ \\
\hline Aspartate aminotransferase & $32 \mathrm{U} / \mathrm{L}$ \\
\hline Alanine aminotransferase & $47 \mathrm{U} / \mathrm{L}$ \\
\hline Lactate dehydrogenase & $636 \mathrm{U} / \mathrm{L}$ \\
\hline C-reactive protein & $0.63 \mathrm{mg} / \mathrm{dl}$ \\
\hline Sodium & $133 \mathrm{mEq} / \mathrm{L}$ \\
\hline Potassium & $4.9 \mathrm{mEq} / \mathrm{L}$ \\
\hline Blood urea nitrogen & $127 \mathrm{mg} / \mathrm{dl}$ \\
\hline Creatinine & $6.6 \mathrm{mg} / \mathrm{dl}$ \\
\hline Estimated glomerular filtration rate & $5.4 \mathrm{ml} / \mathrm{min} / 1.73 \mathrm{~m}^{2}$ \\
\hline Brain natriuretic peptide & $4566 \mathrm{pg} / \mathrm{ml}$ \\
\hline Plasma renin activity & $\geq 20 \mathrm{ng} / \mathrm{ml} / \mathrm{h}$ \\
\hline Plasma aldosterone concentration & $433 \mathrm{pg} / \mathrm{ml}$ \\
\hline \multicolumn{2}{|l|}{ Autoantibody test } \\
\hline Antinuclear antibody & 320 index (speckled pattern) \\
\hline Anti-RNA polymerase III antibody & $\geq 150$ \\
\hline Anti-topoisomerase I antibody & Negative \\
\hline Anti-centromere antibody & Negative \\
\hline Anti-RNP antibody & Negative \\
\hline Anti-SSA antibody & Negative \\
\hline Anti-SSB antibody & Negative \\
\hline PR3-ANCA & $<1.0 \mathrm{IU} / \mathrm{ml}$ \\
\hline MPO-ANCA & $1.1 \mathrm{IU} / \mathrm{ml}$ \\
\hline \multicolumn{2}{|l|}{ Urinalysis } \\
\hline $\mathrm{pH}$ & 5 \\
\hline Specific gravity & 1.012 \\
\hline Protein & $2+$ \\
\hline Glucose & - \\
\hline Occult blood & $3+$ \\
\hline
\end{tabular}

Table 1 Laboratory data on admission (Continued)

\begin{tabular}{ll}
\hline Laboratory test & Result \\
\hline Red blood cells & $1-4 / \mathrm{LPF}$ \\
White blood cells & Countless/HPF \\
Epithelial cell casts & $1-4 / \mathrm{HPF}$ \\
Granular casts & $1-4 / \mathrm{LPF}$ \\
Waxy casts & $1-4 / \mathrm{whole}$ field \\
NAG & $20 \mathrm{U} / \mathrm{L}$ \\
$\beta_{2}$-Microglobulin & $321 \mathrm{\mu g} / \mathrm{L}$ \\
24-h urine collection & \\
Urinary volume & $290 \mathrm{ml} /$ day \\
Creatinine clearance & $1.3 \mathrm{ml} / \mathrm{min}$ \\
Protein & $354 \mathrm{mg} /$ day \\
Glucose & $0.03 \mathrm{~g} /$ day \\
\hline
\end{tabular}

Abbreviations: PT-INR prothrombin time-international normalized ratio, APTT activated partial thromboplastin time, anti-RNA polymerase III antibody antiribonucleic acid polymerase III antibody, anti-RNP antibody antiribonucleoprotein antibody, anti-SSA antibody anti-Sjögren's syndrome-related antigen $A$ antibody, anti-SSB antibody anti-Sjögren's syndrome-related antigen $B$ antibody, PR3-ANCA proteinase-3-antineutrophil cytoplasmic antibody, MPOANCA myeloperoxidase-antineutrophil cytoplasmic antibody, LPF low-power field, HPF high-power field, NAG N-acetyl- $\beta$-D-glucosaminidase

Pathological examination is necessary to make a definite diagnosis, but it is difficult to perform because of invasiveness. Our patient demonstrated typical pathological findings of multiple vacuoles in the medial muscle layer, leading to a definite diagnosis. As a category of nonarteriosclerotic and noninflammatory vascular disease, fibromuscular dysplasia and cystic medial necrosis are important differential diagnoses [14-16]. The common histological feature of fibromuscular dysplasia is medial fibrodysplasia. The collagenized regions alternate with thinned areas of media typically [14]. Clinical features of fibromuscular dysplasia are present in young females and have a predisposition for the medium-sized arteries, especially the renal artery [17]. Cystic medial necrosis occurs in the aorta and large vessels of patients with Marfan syndrome [18] and causes arterial dissection due to disruption of the medial elastic fiber based on congenital fragility of elastic fiber [14]. These clinical and histological features of fibromuscular dysplasia and cystic medial necrosis can be distinguished from SAM. Management of SAM involves embolization, stenting, or surgical resection of the injured arteries [2, 3], though SAM has also been reported to disappear naturally in some cases [19].

SRC is a rare and life-threatening complication of SSc. Without appropriate treatment, it results in renal death and high mortality [5]. SRC is characterized by malignant hypertension and acute renal failure. Although its pathogenesis is incompletely understood [20], it has been considered that proliferation of renal vascular intima [21] and renal vasospasm (so-called "renal 

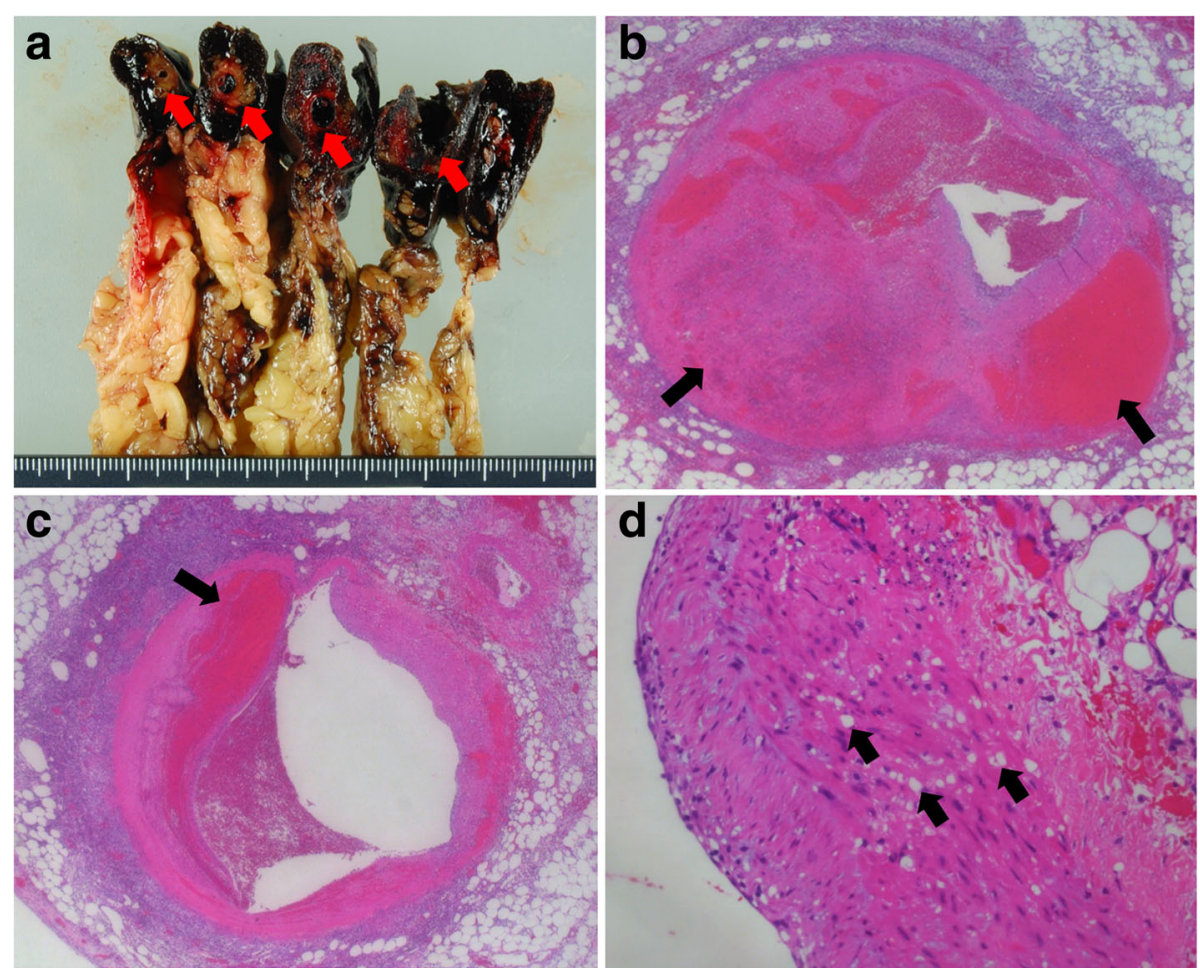

Fig. 2 Pathological findings of the gastroepiploic artery. Macroscopic specimen of gastroepiploic artery (red arrow) with greater omentum (a). The gastroepiploic artery was surrounded by hematoma. The arterial wall was dissected (black arrow), and the dissected cavity was filled with hematoma and fibrin (b and $\mathbf{c}$; H\&E stain; original magnification, 20x). Multiple vacuoles (black arrow) were displayed in the medial muscle layer (d) H\&E stain; original magnification, 40X)

Raynaud") [22] may cause decreased renal blood flow. In addition, hypotension caused by infections, drugs, or dehydration may also contribute to the decreased renal blood flow [23]. Decreased renal blood flow leads to activation of the renin-angiotensin system and the development of severe hypertension. Steen et al. identified several risk factors associated with SRC, including diffuse skin involvement, disease duration $<4$ years, a recent cardiac event, recent onset of anemia, presence of anti-RNA polymerase III antibodies, and treatment with $\mathrm{PSL} \geq 15 \mathrm{mg} /$ day or cyclosporine within the previous 3 months $[4,6-9]$. Our patient was thus at high risk of developing SRC because of diffuse cutaneous SSc, a disease duration of 1 year, anti-RNA polymerase III antibody positivity, and the administration of PSL $20 \mathrm{mg} /$ day from 25 days before admission. She was prescribed ACE-I and angiotensin II receptor blockers, whose effectiveness has been established in the treatment of SRC $[7,10]$, but her renal outcome was poor. Steen et al. reported that poor prognosis factors associated with SRC were male sex, older age, presence of congestive heart failure, Cre level $>3 \mathrm{mg} / \mathrm{dl}$ at the initiation of treatment, and more than 3 days needed to control blood pressure [10, 24]. Our patient had three of these factors: older age, severe renal dysfunction (Cre $6.4 \mathrm{mg} / \mathrm{dl}$ ) at the initiation of treatment, and $>3$ days required to regulate blood pressure; thus, we believed it might be difficult to rescue her renal function.

To the best of our knowledge, no previous reports have described the obvious relationship between SAM and connective tissue diseases, including SSc and SRC. Therefore, our patient had a very rare condition of coincidental coexisting SAM and SRC. Although these are independent diseases, it is possible that they may have interacted to trigger the development of the other in our patient. We considered two possible mechanisms to explain the development of SRC and the aneurysmal rupture of SAM. First, the SRC may have preceded the onset of aneurysmal rupture of SAM, and the SRC-related hypertension may have triggered the aneurysmal rupture, resulting in intraperitoneal bleeding. Her blood pressure was not elevated before surgery, but SRC-related hypertension may have been masked by hemorrhagic hypotension due to the intraperitoneal bleeding. Second, hemodynamic change due to hemorrhagic hypotension or surgical stress may have contributed to the decreased renal blood flow and may have led to activation of the renin-angiotensin system and the development of SRC. These theories are only hypotheses, but the simultaneous occurrence of SAM and SRC certainly exacerbated the patient's condition. 
In conclusion, both SRC and SAM are uncommon but life-threatening clinical conditions with delayed treatment. We report a very rare case of SSc with SRC coexisting with SAM and presenting with intraperitoneal bleeding. There is no known etiological connection between SAM and SSc or SRC, but it is possible that coexisting SAM and SRC may have interacted to trigger the development of the other in our patient.

\section{Abbreviations}

ACE-I: Angiotensin-converting enzyme inhibitor; BUN: Blood urea nitrogen; Cre: Creatinine; CT: Computed tomography; PSL: Prednisolone; SAM: Segmental arterial mediolysis; SRC: Scleroderma renal crisis; SSc: Systemic sclerosis

\section{Acknowledgements}

Not applicable.

\section{Availability of data and materials}

The authors respect the patient's right to privacy. We have presented all important information in this published article.

\section{Authors' contributions}

SK and EW wrote the manuscript. CT reviewed the manuscript. All authors participated in patient care. All authors read and approved the final manuscript.

\section{Ethics approval and consent to participate}

Approval of the institutional ethics committee was not required, because this is a case report without any experimental trial.

\section{Consent for publication}

Written informed consent was obtained from the patient for publication of this report and any accompanying images. A copy of the written consent is available for review by the Editor-in-Chief of this journal.

\section{Competing interests}

The authors declare that they have no competing interests.

\section{Publisher's Note}

Springer Nature remains neutral with regard to jurisdictional claims in published maps and institutional affiliations.

\footnotetext{
Author details

${ }^{1}$ Department of Rheumatology, Saitama Medical Center, Jichi Medical University, 1-847 Amanuma-cho, Omiya-ku, Saitama 330-8503, Japan. 2 Department of Nephrology, Saitama Medical Center, Jichi Medical University, 1-847 Amanuma-cho, Omiya-ku, Saitama 330-8503, Japan. ${ }^{3}$ Department of Surgery, Sainokuni Higashiomiya Medical Center, 1522 Toro-cho, Kita-ku, Saitama 331-8577, Japan. ${ }^{4}$ Department of Rheumatology, Sainokuni Higashiomiya Medical Center, 1522 Toro-cho, Kita-ku, Saitama 331-8577, Japan.
}

Received: 30 September 2018 Accepted: 23 January 2019

Published online: 20 March 2019

\section{References}

1. Slavin RE, Gonzalez-Vitale JC. Segmental mediolytic arteritis: a clinical pathologic study. Lab Invest. 1976;35(1):23-9.

2. Inada K, Maeda M, Ikeda T. Segmental arterial mediolysis: unrecognized cases culled from cases of ruptured aneurysm of abdominal visceral arteries reported in the Japanese literature. Pathol Res Pract. 2007;203(11):771-8.

3. Ryan JM, Suhocki PV, Smith TP. Coil embolization of segmental arterial mediolysis of the hepatic artery. J Vasc Interv Radiol. 2000;11(7):865-8.

4. Steen VD. Scleroderma renal crisis. Rheum Dis Clin N Am. 2003;29(2):315-33.

5. Hudson M, Baron M, Tatibouet S, Furst DE, Khanna D, International Scleroderma Renal Crisis Study Investigators. Exposure to ACE inhibitors prior to the onset of scleroderma renal crisis-results from the International Scleroderma Renal Crisis Survey. Semin Arthritis Rheum. 2014;43(5):666-72.
6. Bussone G, Berezne A, Pestre V, Guillevin L, Mouthon L. The scleroderma kidney: progress in risk factors, therapy, and prevention. Curr Rheumatol Rep. 2011;13(1):37-43.

7. Penn H, Howie AJ, Kingdon EJ, Bunn CC, Stratton RJ, Black CM, et al. Scleroderma renal crisis: patient characteristics and long-term outcomes. QJM. 2007;100(8):485-94.

8. Steen VD, Medsger TA Jr. Case-control study of corticosteroids and other drugs that either precipitate or protect from the development of scleroderma renal crisis. Arthritis Rheum. 1998;41(9):1613-9.

9. Steen VD, Medsger TA Jr, Osial TA Jr, Ziegler GL, Shapiro AP, Rodnan GP. Factors predicting development of renal involvement in progressive systemic sclerosis. Am J Med. 1984;76(5):779-86.

10. Steen VD, Costantino JP, Shapiro AP, Medsger TA Jr. Outcome of renal crisis in systemic sclerosis: relation to availability of angiotensin converting enzyme (ACE) inhibitors. Ann Intern Med. 1990;113(5):352-7.

11. Steen VD, Mayes MD, Merkel PA. Assessment of kidney involvement. Clin Exp Rheumatol. 2003;21(3 Suppl 29):S29-31.

12. Slavin RE, Cafferty L, Cartwright J Jr. Segmental mediolytic arteritis: a clinicopathologic and ultrastructural study of two cases. Am J Surg Pathol. 1989;13(7):558-68

13. Slavin RE, Saeki K, Bhagavan B, Maas AE. Segmental arterial mediolysis: a precursor to fibromuscular dysplasia? Mod Pathol. 1995;8(3):287-94.

14. Baker-LePain JC, Stone DH, Mattis AN, Nakamura MC, Fye KH. Clinical diagnosis of segmental arterial mediolysis: differentiation from vasculitis and other mimics. Arthritis Care Res (Hoboken). 2010;62(11):1655-60.

15. Hellstern V, Aguilar Perez M, Kohlhof-Meinecke P, Bazner H, Ganslandt O, Henkes $\mathrm{H}$. Concomitant retroperitoneal and subarachnoid hemorrhage due to segmental arterial mediolysis: case report and review of the literature. Clin Neuroradiol. 2018;28(3):445-50.

16. Pillai AK, lqbal SI, Liu RW, Rachamreddy N, Kalva SP. Segmental arterial mediolysis. Cardiovasc Intervent Radiol. 2014;37(3):604-12.

17. Khoury MH, Gornik HL. Fibromuscular dysplasia (FMD). Vasc Med. 2017;22(3): 248-52.

18. Yuan SM, Jing H. Cystic medial necrosis: pathological findings and clinical implications. Rev Bras Cir Cardiovasc. 2011;26(1):107-15.

19. Sakano T, Morita K, Imaki M, Ueno H. Segmental arterial mediolysis studied by repeated angiography. Br J Radiol. 1997;70(834):656-8.

20. Mouthon L, Berezne A, Bussone G, Noel LH, Villiger PM, Guillevin L. Scleroderma renal crisis: a rare but severe complication of systemic sclerosis. Clin Rev Allergy Immunol. 2011;40(2):84-91.

21. Charles C, Clements P, Furst DE. Systemic sclerosis: hypothesis-driven treatment strategies. Lancet. 2006;367(9523):1683-91.

22. Cannon PJ, Hassar M, Case DB, Casarella WJ, Sommers SC, LeRoy EC. The relationship of hypertension and renal failure in scleroderma (progressive systemic sclerosis) to structural and functional abnormalities of the renal cortical circulation. Medicine. 1974;53(1):1-46.

23. Bose N, Chiesa-Vottero A, Chatterjee S. Scleroderma renal crisis. Semin Arthritis Rheum. 2015:44(6):687-94.

24. Mouthon L, Bussone G, Berezne A, Noel LH, Guillevin L. Scleroderma renal crisis. J Rheumatol. 2014:41(6):1040-8.

\section{Ready to submit your research? Choose BMC and benefit from:}

- fast, convenient online submission

- thorough peer review by experienced researchers in your field

- rapid publication on acceptance

- support for research data, including large and complex data types

- gold Open Access which fosters wider collaboration and increased citations

- maximum visibility for your research: over $100 \mathrm{M}$ website views per year

At BMC, research is always in progress.

Learn more biomedcentral.com/submission 